\title{
UN NUEVO CRUCIFICADO DE FRANCISCO PACHECO
}

\author{
por Juan Luis Rav PRIETo
}

En el crucificado de El Coronil, el más antiguo de los conocidos hasta ahora, aparecen significativas variantes iconográficas y formales con respecto a los planteamientos teóricos de Pacheco e incluso con respecto al resto de sus crucificados. Por lo que se puede inferir que en 1611 el maestro no había terminado de fijar su emblemática imagen del Crucificado, o en todo caso, seguía muy de cerca las indicaciones de un patrono tan exigente y versado en de los temas iconográficos como el Duque de Alcalá.

In the crucified Christ of El Coronil, the oldest known to date, there are significant iconographic and formal variants with respect to Pacheco's own theoretical principles and even to the rest of his crucifixions. It can thus be deducted that in 1611 the artist had not yet finally established his emblematic image of the «Crucificado», or at least that he was following very closely the instructions of a patron as demanding and well-versed in iconographical matters as the Duke of Alcalá.

Este pequeño crucificado, hoy transformado en cruz de altar, (fig. 1 y 2 ) fue localizado en la parroquia de Nuestra Señora de Consolación de El Coronil (Sevilla) por el equipo que realizó el inventario artístico de la localidad a petición del Ministerio de Cultura 1 . Está pintado al óleo sobre la propia cruz de madera, y resaltado por un fondo oscuro y neutro como si reemplazara visualmente una imagen escultórica, con un tratamiento semejante al que es frecuente en otros ejemplares de la época. Mide 40,6 x 25,6 cms., está firmado (fig. 3) y

1. El equipo estaba formado por los licenciados: Femando Amores Carredano, María Luisa Cano Navas, María Domínguez y Domínguez Adame, María Antonia Durán Montero, Juan Femández Lacomba, Fuensanta García de la Torre, Pedro Respaldiza Lama, Femando Rubio García y el autor de este trabajo. El crucifijo fue dado a conocer y reproducido en dicho inventario: VV.AA. Inventario Artístico de Sevilla y su Provincia. Madrid, 1985, pág. 231, lám. 50. 
fechado bajo los pies de Cristo: O.F.P., 1611, con el anagrama, letras y cifras habituales en otras obras tempranas de Pacheco 2.

Los bordes laterales de esta cruz pintada presentan unas perforaciones que inducen a pensar que estuvo ensamblada en un marco, crucifijo o retablo que le daría una mayor prestancia y que su función primitiva no fue la de humilde cruz de altar. Estos agujeros fueron posteriormente inutilizados y taponados con cera, al montarse la peana.

Aunque, evidentemente, se trata de una obra menor, presenta una serie de variantes de interés con respecto al resto de los crucificados de Pacheco. Quizás por ser anterior, o más bien, por imposición del cliente, su concepción es más dramática y su planteamiento iconográfico no sigue al pie de la letra la elaborada preceptiva que definirá después para este tema en el Arte de la Pintura. Por otra parte, la equilibrada composición depende tanto de los rígidos condicionantes del formato y de la iconografía, como de la consciente búsqueda de un modelo ideal de Crucifixión que no lograría plasmar plenamente hasta 1614, en el Cristo de la colección Gómez-Moreno, paradigma de lo que serán sus otras versiones del tema ${ }^{3}$.

Estudiando el crucificado de El Coronil podemos observar que, en el momento de creación del tipo ideal, o en sus primeros tanteos, debieron intervenir como factores fundamentales la admiración -nunca disimulada- a Miguel Angel y el extraordinario desarrollo de la escultura sevillana contemporánea. En efecto, aquí refunde académicamente las dos imágenes que tenía por creaciones del genial maestro italiano: El Cristo expirante diseñado para Vittoria Colonna, bien conocido en Sevilla a través de grabados ${ }^{4}$, y el crucificado traído a la ciudad por el platero Franconio en 1597, tantas veces alabado por Pacheco y que hoy sabemos que no era obra del gran florentino sino una derivación más o menos indirecta, debida materialmente a Jacopo del Duca 5 .

2. El anagrama compuesto por las iniciales enlazadas rodeado por la $\mathrm{O}$ inicial de "Opus" es el característico aunque no se sitúa sobre la fecha, sino a su lado (fig. 3).

3. Sobre el crucificado modélico véase: GOMEZ MORENO, Manuel: El Cristo de San Plácido. Pacheco se cobra un descubierto que tenian con él Velázquez, Cano y Zurbarán. Boletín de la Sociedad Española de Excursiones. Madrid, 1916, págs. 177-188.

BROWN, Jonathan: Imágenes e ideas en la pintura española del siglo XVII. Madrid, 1980, págs. 91 y 92.

PACHECO, Francisco: Arte de la Pintura, edición, introducción y notas de Bonaventura BASSEGODA Y HUGAS, Madrid, 1990, págs. 18-20 y 713-749,

4. Buena prueba de ello es la escultura del Cristo de la Expiración de la cofradía sevillana del Museo, realizado por Marcos Cabrera en 1575. Esta circunstancia ha sido puesta de manifiesto por MORALES, Alfredo J. y SERRERA, Juan Miguel: Aportaciones a la obra de Jerónimo Hernández, Archivo Español de Arte, 1981. núm. 216, pág. 410.

5. Sobre la autoría: GOMEZ MORENO, M.: Obras de Miguel Angel en España. Archivo Español de Arte y Arqueología, 1930, págs. 193 y 194. 
En el de Vittoria Colonna se inspirarían la horizontalidad de los brazos, la expresión del rostro e incluso el modelo de aureola, elementos que repiten en la época el Grecø o Borgianni, sin embargo nuestro maestro ha eliminado la torsión torácica del original. En el de Franconio encontró la fuente para la serena y simétrica disposición del cuerpo o de las manos cerradas, rasgos mantenidos en los ejemplares de 1614 y 1615 porque encajaban perfectamente con el sentido de la mesura y del decoro que el maestro sevillano pretendía otorgar a la imagen-síntesis del cristianismo.

No olvidemos tampoco que el carácter equívoco del formato convierte al crucificado en un "trompe l'oeil" y nos advierte de la posible influencia de la escultura del momento, evidente también en el Cristo de la colección Gómez Moreno ${ }^{6}$. Así es lógico que la cabeza o la dureza lineal del contorno, en general, o del sudario en particular, recuerdan obras de Núñez Delgado ${ }^{7}$. Este tipo de paño manierista será sustituido en los crucificados posteriores por los modelos más airosos, naturalistas, y de mayor "decoro" derivados, posiblemente, de las esculturas de Montañés.

La búsqueda de una imagen ideal de Cristo en la Cruz conduce inevitablemente a una preocupación por las proporciones canónicas del cuerpo humano que ha de encarnar al mismo Dios. Aunque se acerca, en este crucifijo, a las recomendaciones del "Arte de la Pintura", pues la altura de diez rostros equivale a la distancia entre las manos, la sobrepasa en exceso, alargando los brazos y añadiendo una tercia a la altura total, como proponía Juan de Arfe. Esto nos podía hacer pensar que Pacheco todavía en 1611 no había elaborado su propia teoría de proporciones, siguiendo especialmente a Durero, y que aquí es deudor de Arfe tanto en este aspecto, como en la complexión anatómica que de ello se deriva 8 .

El Crucificado de Miguel Angel. Archivo Español de Arte y Arqueología, 1933, pág. 81 y ss.

Atribuye a Jacopo del Duca: PROSKE, Beatrice G.: Juan Martínez Montañés. Sevillian Sculptor, New York, 1967, págs. 41 y 149, nota 159.

Pero hay que tener en cuenta la vieja relación documentada con un ciborio diseñado por Miguel Angel en sus últimos días para Santa María de los Angeles. LAVAGNINO, Emilio: Di un ciborio de Jacopo del Duca. Rivista del R. Istituto d'Archeología e Storia dell Arte. Roma, 1930, VIII, pág. 104. También refuerza la relación con Miguel Angel PHILLIPS, John Goldsmith: A crucifixión group after Michelangelo. Bulletin Metropolitan Museum of Art. New York, 1937, pág. 210-211.

6. GOMEZ MORENO, M.: El Cristo de San Plácido..., pág. 182.

7. Véase reproducido por LAFUENTE FERRARI, Enrique: Esculturas en marfil de Gaspar Núñez Delgado. Arte Español, Madrid, 1950. pág. 6-11, fig. 5. Aunque el sudario es más estilizado, mantiene la misma disposición, se ata con cuerdas, dejando la pierna izquierda desnuda y produciendo pliegues y un bullón central semejante.

8. ARFE VILAFAÑE, Juan de: De Varia conmesuración para la esculptura y achitectura. Sevilla, 1585. Ed. facsímil, Madrid, 1974, libro III, título I, cap. I, fol. 3 y fig. del fol. 13.

La teoría propia derivada del Durero la expone PACHECO, Francisco: Arte de la Pintura. Edi- 
Tampoco sigue el sistema iconográfico de los crucificados conocidos de $\mathrm{Pa}$ checo, pero no está fuera de la ortodoxia de su tratado. Se ajusta perfectamente al modelo de Cristo expirante allí descrito y del que hasta ahora no se conocía ningún ejemplo de su mano:

"Cristo vivo, con lágrimas, en la expiración, con la autoridad de San Pablo. La llaga del costado pintada con sangre y agua, que se vea distintamente, de que da testimonio el amado Discípulo" 9.

En el caso que nos ocupa se han observado estrictamente todas estas recomendaciones: la sangre brota clara y copiosamente de las llagas, bañando la cruz y cayendo sobre la calavera simbólica. Los ojos con lágrimas contenidas sugieren todo el dolor posible, sin caer en el exceso y estos elementos dramáticos han sido equilibrados por la estática composición, tal como preconizará en otro lugar:

"El rostro con majestad y decoro sin torcimiento feo, o descompuesto, así como convenía a la soberana grandeza de Cristo Nuestro Señor" 10.

Es decir, que su estética de la contención exigía simetría, claridad iconográfica y honestidad en el sudario, como pedía también, siguiendo a Molano "porque en la cruz era Pontífice sumo y sacrificio grato" 11 .

La ausencia del supedáneo o del característico cuarto clavo nos induce a pensar que Pacheco, en 1611, aún no había elaborado, en colaboración con sus polémicos contertulios, la compleja justificación del crucificado de cuatro clavos 12 , que quizás fuera sugerida por las lecturas de Angelo Rocca y Pedro de Medina, la presencia de ejemplares significativos como el de Franconio, Martí-

ción de F.J. Sánchez Cantón, Madrid, 1956, págs. 387, 391 y 392. Su estimación por la obra de Arfe, en el Prólogo pág. 5. Y su deuda en el estudio anatómico, pues da "general noticia de anatomía" no hallándose "tanto junto en un autor nuestro" (T. I. pág. 424). Compárense los modelos anatómicos de Arfe (Op. cit., fol. 13 y 20) con la figura del Cristo.

Véase también en PACHECO, F.: Arte de la Pintura, ed. 1990 la nota de BASSEGODA, pág. 65-66.

9. PACHECO, F.: Op. cit., T. II, pág. 361.

10. Ibídem., T. II, pág. 377. Reflexión de Francisco de Rioja a partir de un Crísto de Pacheco.

11. Ibídem., T. II, pág. 402. Comentario de Pacheco sobre la conveniencia de cubrir a Cristo con un sudario, apoyándose en una cita de Molano. MOLANI, Ionnanis: De Historia SS. Imaginum et Picturarum, pro vero earum usu contra abusu. Lugduni, 1619, pág. 481.

12. Sobre el método de trabajo de Pacheco en las cuestiones teóricas y la colaboración de sus contertulios véase BROWN, J.: Imágenes... pág. 33-56. Sin embargo deben matizarse sus opiniones respecto a que el Arte de la Pintura sea una creación conjunta de esta supuesta "Academia" de Pacheco, según Bassegoda: "Este tipo de prácticas participativas presentes en el Arte no debe hacernos creer que éste es el resultado lineal de un debate en el seno de un grupo intelectual determinado. Sin pretender negar la evidencia de esos nombres y esas opiniones que el Arte nos transmite queremos insistir ahora en el protagonismo de Pacheco en la obra". Vid. PACHECO, F.: Arte..., 1990, introducción pág. 24. 
nez Montañés en Sevilla, o el conocimiento de otros ejemplos en su viaje a Castilla precisamente realizado en $1611^{13}$, sabemos que al menos la mayor parte de los textos utilizados por Pacheco habían sido editados. En cualquier caso también cabe la posibilidad de que en nuestro crucificado Pacheco se limitara a seguir las indicaciones iconográficas de un cliente que poseía un criterio iconográfico propio tan relevante como el Duque de Alcalá, olvidándose, por el momento, de sus propias ideas.

Otro elemento diferenciador con los ejemplares posteriores es la calavera invertida que sirve de receptáculo a la sangre derramada por Cristo, convirtiendo la dramática representación en símbolo de salvación, que se visualiza en el cráneo de Adán, la cabeza de la humanidad y el primer receptor de la sangre salvadora ${ }^{14}$. Esta relación iconográfica le era familiar a Pacheco, tanto por las imágenes tradicionales o los grabados contemporáneos -los realizados a partir de diseños de Miguel Angel ya citados- como por los textos hagiográficos de Pedro de Medina que tanto apreciaba. El hecho de que no aparezca en los crucificados de 1614 y 1615 ni en el Arte de la Pintura puede estar en conexión con las ideas de Molano, quien la rechazaba por considerarlas incompatibles con la ortodoxia bíblica 15 . Es interesante tenerlo en cuenta como precedente, hasta ahora desconocido, de obras de alumnos tan próximos y relevantes como Velázquez, crucificado de 1631, y Alonso Cano, Cristo de 1646.

El título de la cruz merece una atención especial (fig. 4 y ss.) puesto que su definición y fijación fue motivo de una aguda controversia dentro del círculo de intelectuales que rodean a Pacheco (su supuesta Academia) y que lo enconado de la disputa obligó a Pacheco a mantenerse al margen y a silenciar el problema en "el Arte" 16. Además nuestro título presenta diferencias significativas con res-

13. Sobre el comienzo de la preocupación por el tema: GOMEZ MORENO, con su peculiar perspicacia comenta: "y échase a ver que Pacheco hubo de asaltarle el problema (iconográfico del crucifijo con cuatro clavos) durante su viaje por Castilla en 1611, viendo en Madrid y en el Escorial varias imágenes tales". Op. cit., pág. 181, así pues, aunque se interesará a la llegada del Cristo de Franconio, no se decidió a defender la nueva imagen hasta confrontarla con otros ejemplares antiguos. (PACHECO, F.: Op. cit., T. II, pág. 385-387) siguiendo su criterio arqueológico de pintor erudito. Este viaje fue determinante por lo que nuestro crucificado debió ser realizado poco antes de emprenderlo. Para el planteamiento teórico le resultarían imprescindibles: MEDINA, Pedro de: Victoria gloriosa y excelencias de la esclarecida cruz de Jesu Christo Nuestro Señor, Granada, 1604. Todo el capítulo 48 del libro I, especialmente las págs. 403 y 408 . S. BRIGITAE: Revelationes..., Antuarpiae, 1611, cap. LXX, págs. 272 y 276.

14. STAUDE, W. Le crâne-calice au pied de la Croix. La Reveu des Arts. París, 1954.

MEDINA, Op. cit., pág. 185-190.

15. MOLANI, Op. cit., pág. 501-503.

16. VV.AA.: Del título de la Cruz de Christo Nuestro Señor, 1619 (sin pie de imprenta). El impreso de la Biblioteca Universitaria de Sevilla que hemos utilizado está incompleto. Véase a partir del fol. 1 Vo., donde aparece el texto compuesto por Luis de Alcázar y págs. ss., donde aparece la 
pecto a los crucificados de 1614 y 1615 pues no sigue el texto que le compusiera Luis de Alcázar, objeto de las exaltadas críticas del Duque de Alcalá y de la enérgica defensa de Francisco de Rioja. Por el contrario recoge la mayoría de las opiniones y recomendaciones del Duque. Así los textos griego y latino transcriben exclusivamente las palabras de San Juan (19,9): "Jesús Nazareno Rey de los Judíos".

Los caracteres hebráicos son cuadrados “... que según la más común opinión fueron truxeron de Babilonia y se han conservado hasta hoy en los libros sagrados (...) y esto se escribe así sin que se pueda escribir de otra manera..." 17. Pero la inscripción hebráica contradice la propuesta del duque al añadir el demostrativo "ZETH" 18 refundiendo así el texto citado de San Juan con los de San Lucas $(23,38)$ y San Mateo $(27,37)$.

Es posible, por tanto, que todavía en 1611 no se hubiera planteado la discusión en los términos que muestra la polémica impresa en torno a 1619 , y aunque nuestro texto se alinéa con la ortodoxia exigida por el Duque, no sigue tampoco sus planteamientos al, pie de la letra. Sólo posteriormente, a partir de 1614, cuando el maestro comience a utilizar el pergamino de Luis de Alcázar que sintetiza dialécticamente las variantes de los evangelios canónicos, surgirá la confrontación, que se endurece a partir de 1619 con la publicación de una carta dirigida a Pacheco por el duque, criticando los defectos del título de un Cristo admirado en su propio taller. Carta que será replicada por Francisco de Rioja, continuándose posteriormente la polémica, sin solución, en escritos sucesivos impresos en Sevilla y Barcelona.

Pacheco debió mantenerse al margen de la discusión, como se puede asegurar en este caso, donde aparece más cercano a las tesis del Duque. Más por darle gusto al cliente que por hacerse portavoz neutral de una discusión académica

discusión: la propuesta del Duque y la contrapropuesta de Rioja (Fig. 4 y 5). El interés por la fijación del título se explica por el valor simbólico y cabalístico que tiene en la época. Véase el apartado MEDINA, Pedro de.: Op. cit., lib. II, pág. 316 y ss.

17. Ibídem, fol. 2 vo.

18. Debido al pequeño tamaño de la inscripción y a su deterioro, no resulta totalmente legible. Agradecemos a Don Juan Guillén Torralba, canónigo de la Catedral de Sevilla, su inestimable colaboración, al transcribir la inscripción y hacernos los comentarios pertinentes: La grafía del controvertido "ZETH" no está demasiado clara, lo mismo ocurre con las letras iniciales de Jesús, cuya primera "yod" es muy grande y con las de Nazareno. En las demás persisten las "yod" grandes que se pueden recomponer.

Quizás como el duque afirmaba del otro título de Pacheco (fol. 2): "los caracteres hebreos, por la semejanza, los más dellos se confunden facilmente..." lo que se puede entender como una indirecta contra el pintor.

Los textos griegos y latino no presentan anomalías salvo la falta de una $Z$ y el deterioro de la parte final de la inscripción griega. 
como planteó Brown ${ }^{19}$, ya que su silencio con respecto al título, en la redacción definitiva del Arte (1639), no es nada neutral sino sospechosa de no querer ofender al Duque, y el olvido aparente de un tema tan debatido anteriormente, sólo pretendía no levantar viejas heridas como propugna Bassegoda 20 . En todo caso sí está claro, a partir de este crucificado, que puso sus pinceles a disposición de ambas teorías.

En resumen, a pesar de las limitaciones de formato el interés de la obra se centra en que al ser el primero de los crucificados, conocidos hasta hoy, del maestro sevillano, las variantes iconográficas y compositivas que muestra nos permiten intuir el proceso especulativo que llevó a Pacheco a fijar un tema de tanta trascendencia en la pintura del siglo de oro ${ }^{21}$. Así nos presenta un Pacheco abierto y versátil, con un esquema de trabajo de pintor erudito, tan preocupado por el preciosismo miniaturista, el naturalismo y los problemas de proporciones, como por la exégesis bíblica y lo simbólico, acompañado todo ello por un rigor que, al menos él, entendía de carácter científico.

Es difícil, sin embargo, imaginar al maestro realizando una obra tan limitada, en cuanto a formato y relevancia, en un momento cumbre de su producción. No se explicaría sin el contexto de una creación de mayor envergadura, como ya adelantamos en la descripción inicial, y encargada por un cliente de gran predicamento e influencia sobre el pintor. Si pensamos que El Coronil era por entonces señorío de los Ribera, enseguida se plantea la hipótesis de un encargo del Duque de Alcalá, lo cual explicaría alguna de las características antes analizadas.

Hemos procurado documentar una posible donación ducal, pero sólo hemos encontrado, en un parco inventario del Archivo Parroquial, una vaga referencia al que pudo ser el marco de esta pequeña cruz "de pincel", este dato aunque no certifica el origen de nuestra obra, sí abre ciertas posibilidades 22 .

19. BROWM., Op. cit., pág. 75.

20. PACHECO, F.: Arte..., 1990, pág. 713.

21. El magistral trabajo de Brown sobre el crucificado cobra todo su valor al situar perfectamente en su contexto, tanto la disputa teórica, como la plasmación iconográfica del crucificado a partir de Pacheco, pero con secuelas en todo el siglo de oro. BROWN, Op. cit., pág. 33-56. Su propuesta habrá de ser matizada por las sugerencias de Bassegoda e incluso por lo que podamos aportar con este trabajo.

22. Archivo Parroquial de El Coronil: Libro de protocolo de Fábrica y de ymbentarios de todas las alajas que tiene la Iglesia Parroquial de Nuestra Señora de Consolación desta villa del Coronil./ Sin foliar, en el inventario de 1670.

"Yten una crus de plata toda blanca, con una fechura de Cristo crusificado y de otra parte de pincel, la imagen de Nuestra Señora Sinselada, que pesa, con la madera, once marcos y quatro onsas de plata, en que se comprenden tres pedasos pequeños que se han quitado de dicha Cruz y así mismo tiene el pie de plata, donde encaxa y se ata el belo, que pesa onse onsas y media de plata. 
Si no podemos asegurar con plena certeza una relación de patronazgo del Duque de Alcalá con respecto a esta cruz, valga la anotación del vago documento y el contenido de este trabajo para resaltar la complejidad del proceso de creación artística en un período en el que intervienen muy variados factores: el peso lastrante de la tradición, la ambigua posición del artista, antes intérprete que creador, un sentido total y utilitario, al mismo tiempo, de la obra de arte que valora el ornato y la riqueza más que cualquier otro concepto, las exigencias de un cliente y el papel desempeñado por una élite humanista que quiere convertir la pintura en una ciencia, pero que acaba por perder la perspectiva histórica y el protagonismo artístico al encerrarse en sí misma, y en sus discusiones bizantinas. No se puede olvidar tampoco el carácter complementario y funcional de las artes, en general y en el siglo de oro en particular, pues una obra pictórica como ésta, privada de su posible contexto emblemático (las armas del Duque) y de la riqueza sacral que aportaría la cruz de orfebrería que la pudo contener, pierde gran parte de su sentido.

Yten un belo de damasco carmesí con las armmas del Señor Duque de Alcalá que está en la capilla del Sagrario que sirve de sitial del Santo Cristo".

/Al margen/Se consumió esta cruz y de toda la plata que refiere esta partida se hiso una caldereta de plata con su hisopo por febrero de 1676 


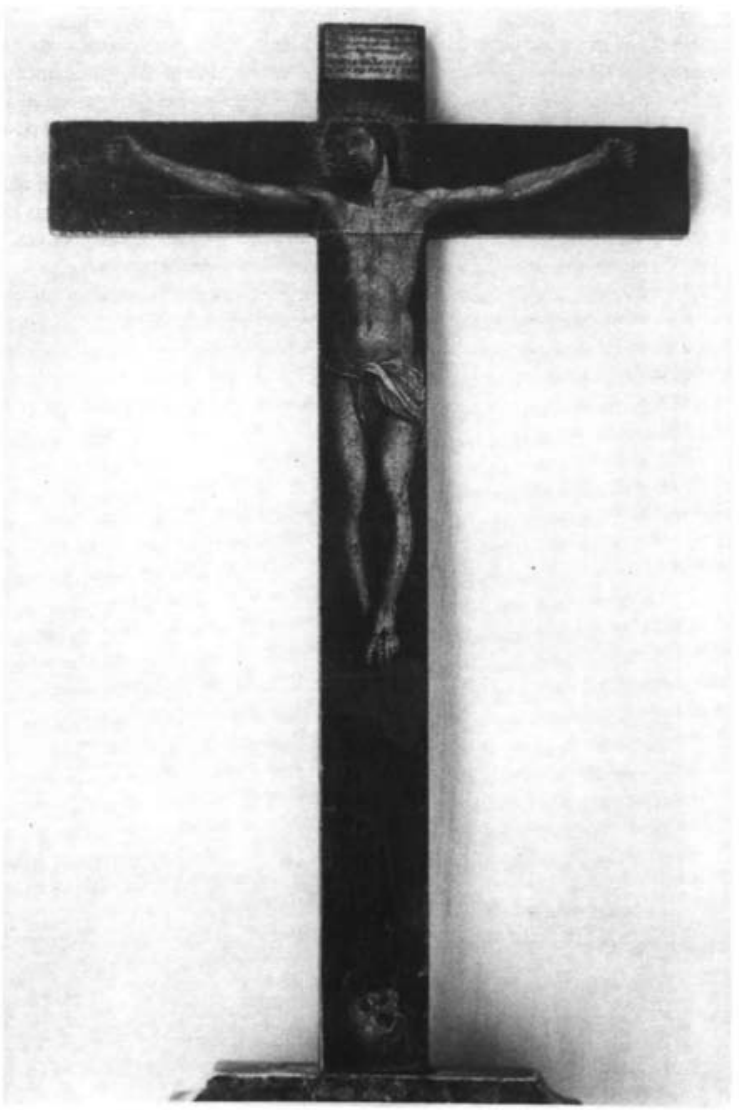

Fig. 1. Crucificado Francisco Pacheco. Parroquia de Nuestra Señora de Consolación. El Coronil (Sevilla). 


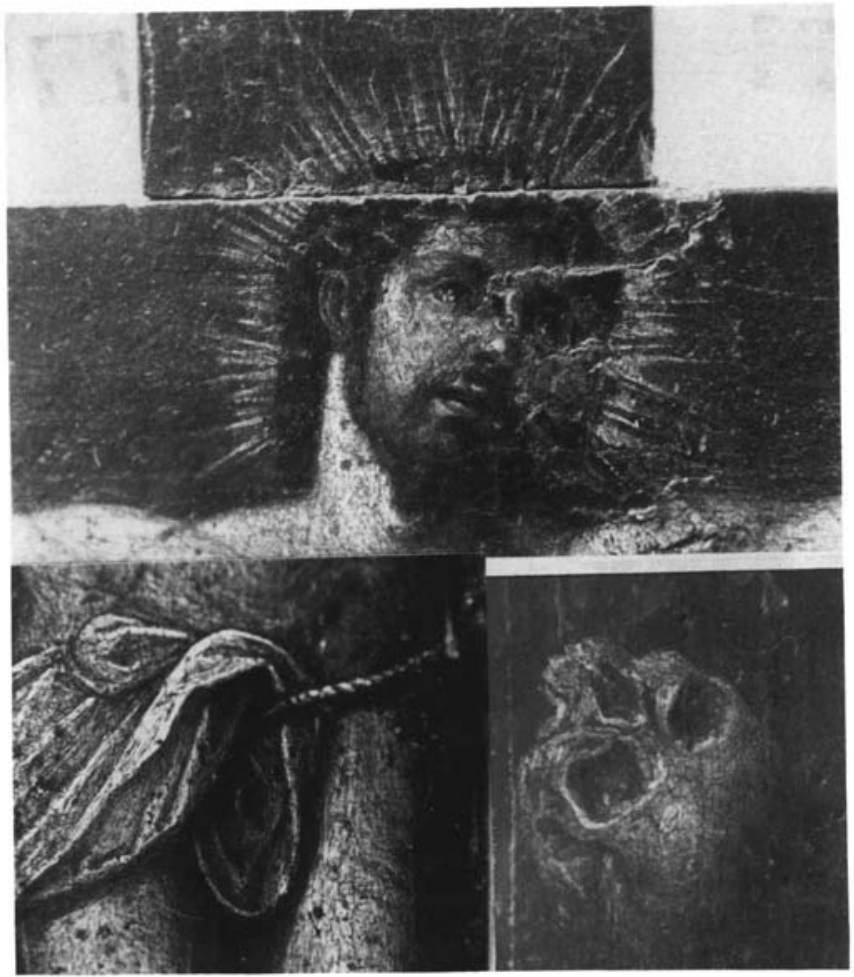

Fig. 2. Detalles. 


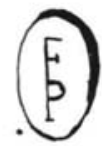

\title{
I 6 I I
}

Fig. 3. Anagrama y fecha.

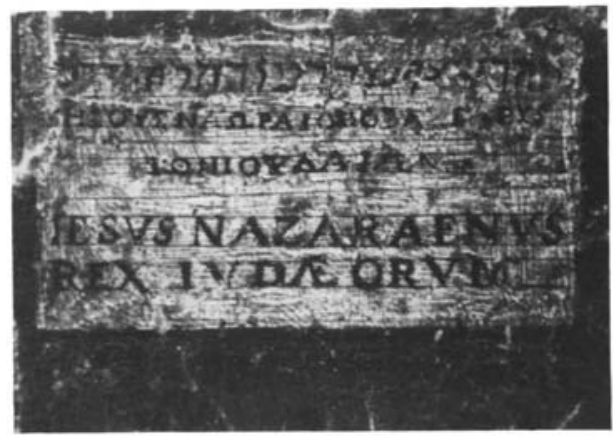

Fig. 4. Titulo de la Cruz, detalle fotográfico.

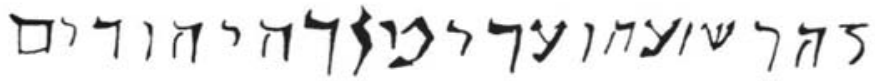 \\ IHEOVENA $\Omega$ PAIOEOBA $\Sigma$ I $\Lambda$ VS}

\author{
$T O N I O V \triangle A I \Omega N$
}

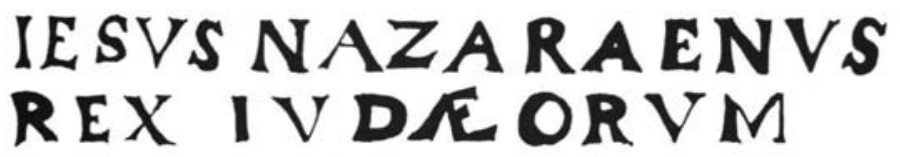

Fig. 5. Título de la Cruz, calco. 


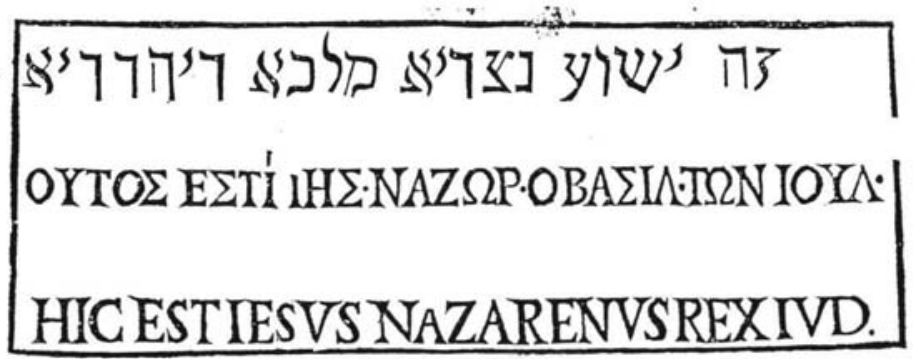

Fig. 6. Tírulo compuesto por Luis de Alcázar.

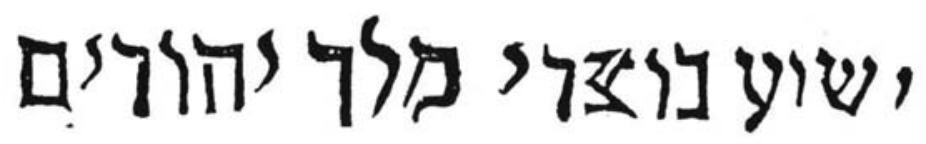

Fig. 7. Propuesta del Duque de Alcalá para la inscripción hebráica.

\section{הבצה ישוע ביצריא. מלבים ריהוריא.}

Fig. 8. Contrapropuesta de Francisco de Rioja. 